\title{
URÂNIO EXAURIDO: Origem, aplicações e suas consequências
}

\author{
Poveda PF \\ Departamento de Mecânica, Instituto Federal de São Paulo, São Paulo, Brasil. \\ Instituto de Pesquisas Energéticas e Nucleares, Universidade de São Paulo, São Paulo, Brasil
}

\begin{abstract}
Resumo. O urânio exaurido, também conhecido como urânio empobrecido, urânio esgotado ou pela sigla DU (do inglês Depleted Uranium) é composto, quase na totalidade, pelo isótopo ${ }^{238} \mathrm{U}$ (urânio-238) e é um subproduto do processo de enriquecimento ou reprocessamento de urânio natural para obtenção do isótopo ${ }^{235} \mathrm{U}$ (Urânio-235), utilizado na físsão em reatores nucleares e bombas. Sua alta densidade $\left(19.050 \mathrm{~kg} / \mathrm{m}^{3}\right), 67 \%$ superior à do chumbo, faz do urânio exaurido um material adequado para diversas aplicações civis e militares. No campo civil ele é usado principalmente como lastro em aeronaves, embarcações e submarinos e como escudo contra radiação. No meio militar é utilizado em projéteis (denominados "penetradores"), blindagens físicas e peças de artilharia em geral. Tais usos são controversos. Embora seja menos tóxico que outros metais pesados (como o arsênico e o mercúrio) e fracamente radioativo, em razão da sua longa meia-vida de cerca de 4,5 bilhões de anos, emite o equivalente a cerca de $60 \%$ da radiação emanada do urânio natural, foi comprovado, a partir de diversos estudos laboratoriais, que é tóxico para mamíferos, ataca o sistema reprodutivo e o desenvolvimento do feto, causando fertilidade reduzida, abortos e deformações nos recém nascidos. Testes citológicos mostraram que, à exposição crônica, o DU é leucogênico, mutagênico e também neuro tóxico.
\end{abstract}

Palavras-chave. Urânio exaurido, DU, Urânio esgotado, Urânio empobrecido, Resíduos radioativos.

\section{DEPLETED URANIUM: Origin, applications and consequences}

Abstract. Depleted uranium is almost entirely composed of the ${ }^{238} \mathrm{U}$ isotope (uranium-238) and is a residue of the enrichment or reprocessing process of natural uranium to obtain the ${ }^{235} \mathrm{U}$ isotope (Uranium-235), used in fission in nuclear reactors and bombs. Its high density $(19,050 \mathrm{~kg}$ $\left./ \mathrm{m}^{3}\right), 67 \%$ higher than that of lead, makes depleted uranium a suitable material for various civil and military applications. In the civilian field it is used mainly as ballast in aircraft, boats and submarines and as a shield against radiation. In the military, it is used in projectiles (called "penetrators"), physical armor and artillery pieces in general. Such uses are controversial. Although it is less toxic than other heavy metals (such as arsenic and mercury) and weakly radioactive, due to its long half-life of about 4.5 billion years, it emits the equivalent of about 
$60 \%$ of the radiation emanating from the natural uranium, it has been proven, from several laboratory studies, that it is toxic to mammals, attacks the reproductive system and the development of the fetus, causing reduced fertility, abortions and deformities in newborns. Cytological tests show that, with chronic exposure, DU is leukogenic, mutagenic and also neurotoxic.

Keywords. Depleted Uranium, DU, Radioactive waste, radioactive contamination

\section{INTRODUÇÃO}

O urânio exaurido, também conhecido como urânio empobrecido, urânio esgotado ou pela sigla DU (do inglês Depleted Uranium) é composto, quase na totalidade, pelo isótopo ${ }^{238} \mathrm{U}$ (Urânio-238) e é um subproduto do processo de enriquecimento ou reprocessamento de urânio natural, visando o aumento da quantidade do isótopo ${ }^{235} \mathrm{U}$ (Urânio-235), utilizado na fissão em reatores nucleares e bombas.

A composição típica do urânio exaurido é $99,6 \%$ a $99,8 \%$ de ${ }^{238} \mathrm{U} ; 0,2 \%$ a $0.4 \%$ de ${ }^{235} \mathrm{U}$ e $0,001 \%$ de ${ }^{234} \mathrm{U}$. Sua alta densidade $\left(19.050 \mathrm{~kg} / \mathrm{m}^{3}\right), 67 \%$ superior à do chumbo, faz do urânio empobrecido um material adequado para diversas aplicações civis e militares. No campo civil ele é usado principalmente como lastro em aeronaves, embarcações e submarinos e como escudo contra radiação. No meio militar é utilizado em projéteis (denominados "penetradores"), conforme mostrado na Figura 1 (1), blindagens físicas e peças de artilharia em geral. Tais usos são controversos. Embora seja menos tóxico que outros metais pesados (como o arsênico e o mercúrio) e fracamente radioativo em razão da sua longa meia-vida, de aproximadamente 4,5 bilhões de anos (2), emite o equivalente a cerca de $60 \%$ da radiação emanada do urânio natural (3). Foi comprovado, a partir de diversos estudos laboratoriais, que o Urânio-238 é tóxico para mamíferos, ataca o sistema reprodutivo e o desenvolvimento do feto causando fertilidade reduzida, abortos e deformações nos recém nascidos (4). Testes citológicos mostraram que, à exposição crônica, o DU é leucogênico, mutagênico e também neuro tóxico (5).

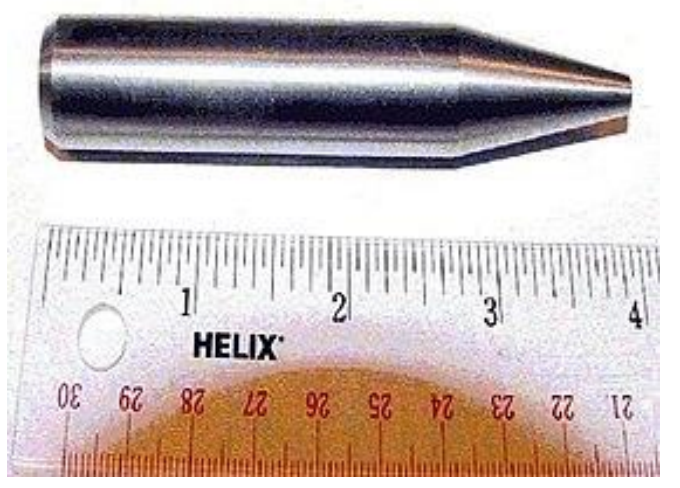

Figura 1. Penetrador de Urânio exaurido (1)

1 ORIGEM E HISTÓRICO DA UTILIZAÇÃO DO URÂNIO EXAURIDO 
O ciclo de combustíveis nucleares envolvendo urânio se iniciou na década de 1940, quando os Estados Unidos e a Grã-Bretanha iniciaram seus programas de armas nucleares. Mais tarde na década de 1950, a França e a União Soviética iniciaram seus programas de armas nucleares e geração de energia elétrica por meio de Reatores de Potência. Atualmente, cerca de 20 países manipulam, de alguma forma, compostos com isótopos de Urânio O urânio empobrecido foi originalmente armazenado como um produto residual (hexafluoreto de urânio) na expectativa de que, com avanços nos processos de enriquecimento, fosse possível extrair quantidades adicionais do isótopo U-235 fissionável. Esta recuperação de extração de urânio-235 residual é atualmente implementada em alguns países, mas não é prática comum no segmento de processamento de combustíveis nucleares (6), em função dos custos envolvidos nesses processos.

Na década de 1970, o Pentágono identificou que os militares soviéticos desenvolveram, para utilização nos tanques utilizados pelos países do Pacto de Varsóvia, blindagem impenetrável para a munição antitanques utilizada pela Organização do Tratado do Atlântico Norte (OTAN). Os pesquisadores do exército americano começaram a buscar o desenvolvimento de materiais para produção de projéteis com capacidade de perfuração dessas blindagens, concluindo pelo uso do urânio exaurido.

Efetivamente, os EUA e demais membros da OTAN utilizaram penetradores de DU na Guerra do Golfo de 1991, na guerra da Bósnia (7), bombardeio da Sérvia, invasão do Iraque em 2003 (8) e ataques aéreos de 2015 contra o ISIS na Síria (9). Estima-se que entre 315 e 350 toneladas de DU foram usadas na Guerra do Golfo de 1991 (10).

\section{ESTOQUE DE URÂNIO EXAURIDO NO MUNDO E PROBLEMAS DECORRENTES}

A maior parte do urânio exaurido existente é armazenado como hexafluoreto de urânio $\left(\mathrm{UF}_{6}\right)$, um sólido cristalino tóxico, em cilindros de aço em pátios de armazenamento a céu aberto próximos às usinas de enriquecimento. Cada cilindro armazena até 12,7 toneladas. Nos EUA, em 2008, havia 686.500 toneladas de $\mathrm{UF}_{6}$ em 57.122 cilindros de armazenamento (11) (12).

$\mathrm{O}$ armazenamento do $\mathrm{UF}_{6}$ apresenta riscos ambientais, de saúde e segurança devido à sua instabilidade química. Quando o $\mathrm{UF}_{6}$ é exposto ao vapor de água no ar, ele reage com a umidade para produzir $\mathrm{UO}_{2} \mathrm{~F}_{2}$ (fluoreto de uranila), um sólido, e $\mathrm{HF}$ (fluoreto de hidrogênio), um gás, ambos altamente solúveis e tóxicos.

Há registros de vários acidentes envolvendo hexafluoreto de urânio nos Estados Unidos, incluindo um em que 32 trabalhadores foram expostos a uma nuvem contendo $\mathrm{UF}_{6}$ e seus produtos de reação em 1986, numa instalação comercial de processamento de urânio em Gore, Oklahoma. Uma pessoa morreu e outros trabalhadores, com maior exposição, sofreram danos renais de curto prazo (por exemplo, proteína na urina) (13).

Os estoques conhecidos de $\mathrm{UF}_{6}$ no mundo supera um milhão de toneladas conforme mostrado na Tabela 1. 
TAS Journal, vol. 4, n. 4, p. 219 - 240

ISSN 2595-1521

DECEMBER 2020

pedro.poveda@usp.br

Tabela 1. Estoques conhecidos de Urânio exaurido (14)

\begin{tabular}{|c|c|r|c|}
\hline Organização & Países & $\begin{array}{c}\text { Quantidade } \\
\text { estimada de Urânio } \\
\text { Exaurido } \\
\text { (toneladas) }\end{array}$ & $\begin{array}{c}\text { Ano } \\
\text { base }\end{array}$ \\
\hline DOE & Estados unidos & 480.000 & 2002 \\
\hline FAEA & Rússia & 460.000 & 1996 \\
\hline Areva NC & França & 190.000 & 2001 \\
\hline BNFL & Reino Unido & 30.000 & 2001 \\
\hline URENCO & Reino Unido, Alemanha e & 16.000 & 1999 \\
\hline JNFL & Holanda & 10.000 & 2001 \\
\hline CNNC & Japão & 2.000 & 2000 \\
\hline KAERI & China & 200 & 2002 \\
\hline NECSA & Coreia do Sul & 73 & 2001 \\
\hline África do Sul & 60 & 2007 \\
\hline DSO National Laboratories & Singapura & 1.188 .273 & \multirow{2}{*}{} \\
\hline \multicolumn{1}{r|}{ Total } & &
\end{tabular}

Não foram encontrados dados quantitativos de estoque de $\mathrm{UF}_{6}$ no Brasil, entretanto, conforme tratado no próximo tópico, há discussões pontuais no âmbito do Exército Brasileiro defendendo o uso de munição cinética baseada em penetradores de urânio empobrecido (15).

\section{APLICAÇÕES MILITARES DO URÂNIO EXAURIDO}

Devido à sua alta densidade específica, apenas ligeiramente menos denso que o tungstênio, cujas principais reservas estão concentradas na China (65\%) (16), que também é utilizado como munição cinética (penetradores), o urânio exaurido tem sido uma alternativa econômica e estratégica para esse tipo de aplicação, pois os países (potências militares) que demandam essa aplicação possuem amplas reservas disponíveis (como mostrado no quadro da Tabela 1). Um projétil de DU pode ter um diâmetro menor do que um projétil de chumbo equivalente, com menor arrasto aerodinâmico e penetração mais profunda, devido a uma pressão mais alta no ponto de impacto, comparável com similares de tungstênio, conforme mostrado na Tabela 2, a unidade de penetração "RHAe" (Rolled Homogeneous Armor Equivalent) utilizada, foi criada para determinar a resistência de uma blindagem composta (mais de um material), normalmente utilizada em carros de combate, comparada com uma blindagem homogênea (aço puro) (15). Materiais bélicos de DU também costumam ser inerentemente incendiários porque o urânio é inflamável (17) (18), quando pulverizados e submetidos à altas temperaturas. 
Tabela 2. Comparação das capacidades de penetração de Projéteis de Tungstênio com similares de Urânio exaurido (15)

\begin{tabular}{|c|c|c|c|c|}
\hline CALIBRE & MUNICATO & PENETRADOR & País & PENETRAĞLOO EM RHAL \\
\hline $105 \mathrm{~mm}$ & M-426 (DM63) & Tungstênio & Israel & $425 \mathrm{~mm}$ \\
\hline $105 \mathrm{~mm}$ & M-900 & Urânio empobrecido & EUA & $520 \mathrm{~mm}$ \\
\hline $105 \mathrm{~mm}$ & OFL105E2 & Urânio empobrecido & França & $540 \mathrm{~mm}$ \\
\hline $105 \mathrm{~mm}$ & $\mathrm{~T}-2 \mathrm{HP}$ & Tungstênio & China & $560 \mathrm{~mm}$ \\
\hline $105 \mathrm{~mm}$ & Type-95 & Urânio empobrecido & China & $580 \mathrm{~mm}$ \\
\hline $120 \mathrm{~mm}$ & L27 Charm3 & Urânio empobrecido & Reino Unido & $700 \mathrm{~mm}$ \\
\hline $120 \mathrm{~mm}$ & DM-53 & Tungstênio & Alemanha & $810 \mathrm{~mm}$ \\
\hline 120 mm & M-829 A3 & Urânio empobrecido & EUA & $960 \mathrm{~mm}$ \\
\hline
\end{tabular}

Além da aplicação em munições, o urânio exaurido também pode ser usado na blindagem de tanques, prensado entre chapas de aço. Mesmo unidades produzidas antes do desenvolvimento dessa tecnologia, tem passado por atualizações, incorporando essas melhorias.

Outra aplicação possível para o urânio empobrecido é como refletor de nêutrons em bombas de fissão, proporcionando uma explosão mais duradoura e energética, portanto, mais eficiente.

\subsection{Legalidade do uso do Urânio empobrecido em armas}

Em 1996, a Corte Internacional de Justiça (CIJ) se pronunciou sobre a "legalidade da ameaça ou uso de armas nucleares" (traduzido e adaptado pelo autor), concluindo que o direito internacional relacionado às restrições do uso de armas químicas, a Segunda Declaração de Haia de 29 de julho de 1899, a Convenção de Haia IV de 18 de outubro de 1907 e o Protocolo de Genebra de 17 de junho de 1925, não abrangia as armas nucleares, porque seu uso principal ou exclusivo não era destinado a envenenar ou asfixiar. Esta opinião da CIJ era sobre armas nucleares, mas decidiram por incluir o texto "os termos devem entendidos para artefatos que, mesmo sem o objetivo principal de envenenar ou asfixiar, apresentavam esses efeitos colaterais" (texto traduzido e adaptado), caso das aplicações militares do urânio empobrecido, cujo objetivo é destruir material e/ou matar soldados por meio da energia cinética (19).

A Subcomissão de Prevenção da Discriminação e Proteção de Minorias da Comissão de Direitos Humanos das Nações Unidas, aprovou duas moções, a primeira em 1996 (20) e a segunda em 1997 (21). Nos documentos, foram listadas armas de destruição em massa, com efeitos destrutivos indiscriminados ou com potencial de causar ferimentos supérfluos ou desnecessários, incluindo armamentos contendo urânio exaurido. 
Em 2002, a resolução 2001/36 da Subcomissão para a Promoção e Proteção dos Direitos Humanos da ONU, emitiu parecer em que argumenta que o uso de DU em armas, pode violar um ou mais dos seguintes tratados: a Declaração Universal dos Direitos Humanos, a Carta das Nações Unidas, a Convenção do Genocídio, a Convenção das Nações Unidas contra a Tortura, as Convenções de Genebra, incluindo o Protocolo I, a Convenção sobre Armas Convencionais de 1980 e a Convenção de Armas Químicas (22).

O Parlamento Europeu aprovou recorrentemente resoluções recomendando suspensão imediata do uso de munições de urânio exaurido (25) (26) mas França e Inglaterra, os únicos Estados europeus que são membros permanentes do Conselho de Segurança das Nações Unidas, rejeitaram sistematicamente os pedidos para uma proibição (27), sustentando que seu uso é legal, e os riscos colaterais para a saúde são infundados (28).

Em 2007, França, Grã-Bretanha, Holanda e República Tcheca votaram contra uma resolução da Assembleia Geral das Nações Unidas para realizar um debate, sobre os efeitos do uso de armamentos e munições contendo urânio exaurido. Todas as outras nações da União Europeia votaram a favor ou se abstiveram (29). O embaixador da Holanda justificou o seu voto negativo devido à referência no preâmbulo da resolução, "aos potenciais efeitos nocivos do uso de munições de urânio empobrecido sobre a saúde humana e o meio ambiente", que não poderiam ser apoiados por estudos científicos conclusivos conduzidos até então (30). Nenhum dos outros membros permanentes do Conselho de Segurança das Nações Unidas apoiaram a resolução, a China estava ausente, a Rússia se absteve e os Estados Unidos votaram contra (29).

Em dezembro de 2008, 141 Estados apoiaram uma resolução solicitando que três agências da ONU: Programa das Nações Unidas para o Meio Ambiente, Organização Mundial da Saúde e Agência Internacional de Energia Atômica atualizassem suas pesquisas sobre o impacto das munições de urânio exaurido, até o final de 2010, para coincidir com a $65^{\text {a }}$ Sessão da Assembleia Geral, quatro nações votaram contra (Inglaterra, França, Israel e Estados Unidos) (31), impedindo que se buscasse avançar no conhecimento dos impactos da utilização do material.

Em 21 de junho de 2009, a Bélgica se tornou o primeiro país do mundo a proibir "munições e blindagens que contenham urânio em qualquer das suas formas" (32), estendendo à proibição de quaisquer investimentos de origem belga em fabricantes de armas do material (33).

\section{APLICAÇÕES CIVIS E COMERCIAIS DO URÂNIO EXAURIDO}

O uso não militar do urânio empobrecido se destina, principalmente, como corantes, materiais de proteção contra exposição a fontes radioativas e como lastro e contrapesos em geral.

\subsection{Blindagem em câmeras de radiografia industrial}

As câmeras de radiografia industriais utilizam uma fonte de radiação gama de atividade muito alta. O urânio empobrecido é usado como um escudo para proteger os indivíduos da radiação. Normalmente, o escudo (placa) de urânio é envolvido em espuma de poliuretano para proteção térmica, mecânica e contra oxidação (34). 


\subsection{Corantes}

As aplicações de urânio exaurido como corantes, incluem sua incorporação em porcelana dentária (para simular a fluorescência de dentes naturais) e reagentes utilizados em laboratórios de química (por exemplo, acetato de uranila, usado em química analítica e como corante em microscopia eletrônica). Até 1999, concentrações de $10 \%$ de urânio exaurido eram utilizadas na produção do "Jaune $\mathrm{n}^{\circ}$ 17", um pigmento de esmalte amarelo produzido na França pela Cristallerie. $\mathrm{O}_{\mathrm{UF}_{6}}$ era comercializado pela Pierrelatte da Cogéma, que interrompeu sua comercialização em 2000, para produtores de esmalte e vidro (35).

\subsection{Lastros para balanceamento em aeronaves}

Aeronaves que utilizam contrapesos de urânio exaurido como contrapesos para balanceamento e estabilização de asas e superfícies de controle (como no Boeing 747-100), podem conter entre 400 e $1.500 \mathrm{~kg}$ de DU. Esta aplicação é controversa porque o DU pode entrar em contato com o meio ambiente se a aeronave se acidentar. O metal também pode oxidar em um pó fino na presença de chama. Seu uso foi descontinuado em muitas aeronaves mais recentes. A Boeing e a McDonnell-Douglas descontinuaram o uso de contrapesos DU na década de 1980. Urânio empobrecido foi liberado durante a queda de um voo da El Al 1862 em1992 no qual 152 $\mathrm{kg}$ foram perdidos, mas não foram constatadas ocorrências de problemas de saúde (36). Os contrapesos de DU fabricados com revestimento de cádmio não são considerados perigosos enquanto o revestimento estiver intacto (37).

\subsection{Quilha de veleiros}

O barco esportivo Pen Duick VI, projetado em construído na França em 1973, foi equipado com uma quilha de urânio empobrecido. O benefício é que, por causa da densidade muito alta do urânio, a quilha pode ser mais fina para um mesmo peso que outros materiais e, consequentemente, apresentar menos resistência ao deslocamento na água do quilhas construídas com materiais convencionais. Posteriormente, houve substituição por uma quilha de chumbo padrão (38).

\subsection{Calorímetros para detecção de partículas de alta energia}

O urânio exaurido tem sido usado em calorímetros de amostragem, como os detectores D0 (39) e ZEUS (40), utilizados em pesquisas de Física das partículas, em razão de sua alta densidade e radioatividade natural.

\subsection{Receptáculos e Containers em geral para transporte de fontes radioativas}

Em razão da disponibilidade e boa capacidade de conter radiações o urânio empobrecido tem sido muito utilizado como blindagem em receptáculos e containers em geral de materiais radioativos (41). 


\section{EFEITOS PARA A SAÚDE HUMANA DECORRENTES DA EXPOSIÇÃO AO URÂNIO EXAURIDO}

São raros os estudos específicos relacionados aos danos provocados à saúde humana especificamente causados pela exposição ao urânio exaurido. Em geral são associados aos já conhecidos efeitos provocados pelo urânio natural e outros materiais radioativos semelhantes.

$\mathrm{O}$ funcionamento dos rins, cérebro, fígado, coração e vários outros sistemas biológicos, podem ser afetados pela exposição ao urânio porque, além da radioatividade, é um metal tóxico (41). É fracamente radioativo, mas o é "persistentemente" por causa de sua meia-vida longa. As Tabelas 3a e 3b, mostram os diferentes efeitos no corpo humano, decorrentes da exposição em diversas formas e níveis ao Urânio.

Tabela 3a. Efeitos no organismo humano decorrentes da exposição ao Urânio (41)

\begin{tabular}{|c|c|c|c|}
\hline \multicolumn{4}{|c|}{ Informações sobre a toxicidade do Urânio } \\
\hline $\begin{array}{l}\text { Sistema do } \\
\text { corpo }\end{array}$ & Estudos humanos & Estudos animais & Em vitro \\
\hline Renal & $\begin{array}{l}\text { Níveis elevados de excreção } \\
\text { de proteínas, catalase } \\
\text { urinária e diurese }\end{array}$ & $\begin{array}{l}\text { Danos aos túbulos } \\
\text { convolutos proximais, células } \\
\text { necróticas moldadas do } \\
\text { epitélio tubular, alterações } \\
\text { glomerulares }\end{array}$ & Sem estudos \\
\hline Cérebro / SNC & $\begin{array}{l}\text { Diminuição do desempenho } \\
\text { em testes neurocognitivos }\end{array}$ & $\begin{array}{l}\text { Toxicidade colinérgica } \\
\text { aguda; Acumulação dose- } \\
\text { dependente no córtex, } \\
\text { mesencéfalo e } \\
\text { vermis; Mudanças } \\
\text { eletrofisiológicas no } \\
\text { hipocampo }\end{array}$ & Sem estudos \\
\hline DNA & $\begin{array}{l}\text { Aumento de relatos de } \\
\text { câncer }\end{array}$ & $\begin{array}{l}\text { Mutagenicidade aumentada } \\
\text { na urina e indução de } \\
\text { tumores }\end{array}$ & $\begin{array}{l}\text { Células binucleadas com } \\
\text { micronúcleos, inibição da } \\
\text { cinética e proliferação do } \\
\text { ciclo celular; Indução de } \\
\text { cromátide irmã, fenótipo } \\
\text { tumorigênico }\end{array}$ \\
\hline Osso / músculo & Sem estudos & $\begin{array}{l}\text { Inibição da formação do osso } \\
\text { periodontal; e cicatrização de } \\
\text { feridas alveolares }\end{array}$ & Sem estudos \\
\hline Reprodutivo & $\begin{array}{l}\text { Mineiros de urânio têm mais } \\
\text { filhas primogênitas }\end{array}$ & $\begin{array}{l}\text { Atrofia tubular focal } \\
\text { moderada a } \\
\text { grave; vacuolização de } \\
\text { células de Leydig }\end{array}$ & Sem estudos \\
\hline
\end{tabular}


TAS Journal, vol. 4, n. 4, p. 219 - 240

ISSN 2595-1521

DECEMBER 2020

pedro.poveda@usp.br

Tabela 3b. Efeitos no organismo humano decorrentes da exposição ao Urânio (41)

\begin{tabular}{|c|c|c|c|}
\hline \multicolumn{4}{|c|}{ Informações sobre a toxicidade do Urânio } \\
\hline $\begin{array}{l}\text { Sistema do } \\
\text { corpo }\end{array}$ & Estudos humanos & Estudos animais & Em vitro \\
\hline $\begin{array}{l}\text { Pulmões / } \\
\text { respiratório }\end{array}$ & $\begin{array}{l}\text { Nenhum efeito adverso à } \\
\text { saúde relatado }\end{array}$ & $\begin{array}{l}\text { Grave congestão nasal e } \\
\text { hemorragia, lesões } \\
\text { pulmonares e fibrose, edema } \\
\text { e inchaço, câncer de pulmão }\end{array}$ & Sem estudos \\
\hline Gastrointestinal & Vômito, diarréia, albuminúria & $\mathrm{n} / \mathrm{D}$ & $\mathrm{n} / \mathrm{D}$ \\
\hline Fígado & $\begin{array}{l}\text { Nenhum efeito observado na } \\
\text { dose de exposição }\end{array}$ & $\begin{array}{l}\text { Figados gordurosos, necrose } \\
\text { focal }\end{array}$ & Sem estudos \\
\hline Pele & $\begin{array}{l}\text { Não há dados de avaliação } \\
\text { de exposição disponíveis }\end{array}$ & $\begin{array}{l}\text { Células epidérmicas } \\
\text { vacuoladas inchadas, danos } \\
\text { aos folículos capilares e } \\
\text { glândulas sebáceas }\end{array}$ & Sem estudos \\
\hline $\begin{array}{l}\text { Tecidos ao redor } \\
\text { de fragmentos DU } \\
\text { incorporados }\end{array}$ & $\begin{array}{l}\text { Concentrações elevadas de } \\
\text { urina de urânio }\end{array}$ & $\begin{array}{l}\text { Concentrações elevadas de } \\
\text { urina de urânio, perturbações } \\
\text { em testes bioquímicos e } \\
\text { neuropsicológicos }\end{array}$ & Sem estudos \\
\hline $\begin{array}{l}\text { Sistema } \\
\text { imunológico }\end{array}$ & $\begin{array}{l}\text { Fadiga crônica, erupção na } \\
\text { pele, infecções nos ouvidos } \\
\text { e nos olhos, perda de cabelo } \\
\text { e peso, tosse. Pode ser } \\
\text { devido à exposição química }\end{array}$ & Sem estudos & Sem estudos \\
\hline Olhos & Sem estudos & $\begin{array}{l}\text { Conjuntivite, irritação, } \\
\text { inflamação, edema, } \\
\text { ulceração dos sacos } \\
\text { conjuntivais }\end{array}$ & Sem estudos \\
\hline Sangue & Sem estudos & $\begin{array}{l}\text { Diminuição da contagem de } \\
\text { hemácias e concentração de } \\
\text { hemoglobina }\end{array}$ & Sem estudos \\
\hline Cardiovascular & $\begin{array}{l}\text { Miocardite resultante da } \\
\text { ingestão de urânio, que } \\
\text { terminou } 6 \text { meses após a } \\
\text { ingestão }\end{array}$ & Sem efeitos & Sem estudos \\
\hline
\end{tabular}

Em conflitos militares envolvendo munições com DU, a principal preocupação é a inalação de partículas, decorrentes dos impactos de projéteis (43). Quando as munições de urânio exaurido penetram nas blindagens e/ou queimam, elas produzem óxidos de urânio na forma de poeira que pode ser inalada ou penetrar no corpo humano pelos ferimentos causados. 
A Figura 2 ilustra as vias de exposição, contaminação, comportamento dentro do corpo e órgãos afetados (41).

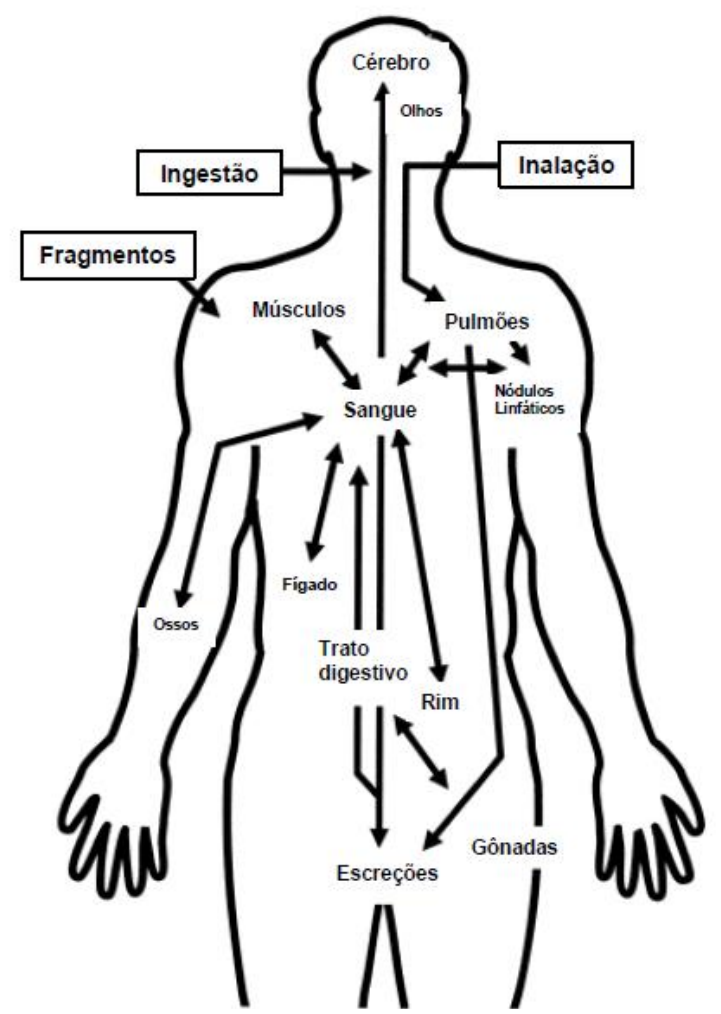

Figura 2. Comportamento e efeitos do Urânio esgotado no corpo humano (41)

(traduzido e adaptado pelo autor)

O Instituto de Tecnologia Nuclear e Proteção contra Radiação de Attiki na Grécia, constatou que "o aerossol produzido durante o impacto e a combustão de munições de urânio exaurido pode contaminar grandes áreas ao redor dos locais de impacto e ser inalado por civis e militares" (44). O uso de DU em munições incendiárias é controverso por causa dos potenciais efeitos adversos à saúde e sua liberação no meio ambiente (45).

Entretanto, apesar dos inúmeros indícios dos potenciais malefícios, o Departamento de Defesa dos EUA alega que nenhum câncer humano de qualquer tipo foi visto como resultado da exposição ao urânio natural ou exaurido (46). Os militares há muito tempo implementam procedimentos para redução de riscos para suas tropas (47) e alguns estudos realizados concluíram que os veteranos que usaram munições aprimoradas com DU não sofreram aumento de incidência de câncer. Os efeitos do DU nas populações civis são, no entanto, desconhecidos e motivo de controvérsias intensas e contínuas.

Em direção contrária ao Departamento de Defesa dos EUA, em 1997, médicos do Exército britânico alertaram o Ministério da Defesa que a exposição ao urânio empobrecido aumentava o risco de desenvolver câncer de pulmão, linfático e cérebro, e recomendaram uma 
série de precauções de segurança (48). A Royal Society pediu, que fosse dada atenção urgente aos possíveis impactos ambientais e à saúde das pessoas expostas ao urânio exaurido, expressando seu apoio ao apelo do Programa Ambiental das Nações Unidas para uma avaliação científica dos locais atingidos (49). No início de 2004, o Serviço do Tribunal de Recursos de Pensões do Reino Unido atribuiu, como causa de defeitos de nascença do filho de um veterano de combate da Guerra do Golfo, nascido em fevereiro de 1991, o envenenamento do militar por urânio exaurido (50).

\subsection{Efeitos Bioquímicos}

A toxicidade química do urânio empobrecido é idêntica à do urânio natural e cerca de um milhão de vezes maior do que o risco radiológico (51), sendo o rim considerado o principal órgão-alvo (52). Os efeitos do DU na saúde humana são determinados por fatores como a extensão da exposição e se a contaminação foi interna ou externa. Existem três vias principais pelas quais a interação do urânio com o organismo humano pode ocorrer: inalação, ingestão e ferimentos por estilhaços (53), como mostrado na Figura 2. Tipos de resíduos (sólido, particulado ou gasoso), estado de oxidação (por exemplo, metálico ou cerâmico) e a solubilidade do urânio e seus compostos, influenciam na velocidade e volume de absorção, distribuição, eliminação e níveis de toxicidade.

\subsection{Efeitos Radiológicos}

Os efeitos primários da radiação do urânio exaurido puro são devidos às partículas alfa que não viajam muito através do ar e não penetram nas roupas. No entanto, em questão de um mês ou mais, uma amostra de urânio empobrecido puro, com seu decaimento radioativo natural, irá gerar pequenas quantidades de tório-234 e protactínio-234, que emitem partículas beta, mais penetrantes, quase na mesma taxa que o urânio emite raios alfa. Isso ocorre porque o urânio-238 decai diretamente para o tório-234 que, com meia-vida de 24 dias, decai para o protactínio-234, que por sua vez decai em questão de horas para o urânio-234 de longa vida (54). Meia-vidas menores significam atividades radioativas mais altas que, associadas a partículas de radiação mais penetrantes potencializam os danos causados no organismo.

\subsection{Casos conhecidos de utilização e/ou contaminação por urânio exaurido}

\subsubsection{Guerra do Golfo - Militares combatentes (1991)}

Desde 1991, ano do fim da Guerra do Golfo, os veteranos americanos e suas famílias expressaram preocupação com os problemas de saúde subsequentes (55) (56). Em 1999, uma avaliação dos primeiros 1.000 veteranos envolvidos no programa de avaliação médica realizado nos Estados Unidos não encontrou "nenhuma evidência" de doenças, físicas ou mentais (57).

Entretanto, foram relatados, por mais de $25 \%$ dos veteranos, distúrbios do sistema imunológico e outros sintomas abrangentes como dor crônica, fadiga e perda de memória (58). Apesar da negação do governo americano, produtos de combustão de munições de urânio empobrecido estão sendo considerados pelo Comitê Consultivo de Pesquisa independente, como 
causadores de doenças nos veteranos da Guerra do Golfo, já que o DU foi usado, pela primeira vez em grande escala naquele conflito, em quantidade estimada de 320 toneladas, como mostrado na Figura 3. Foi observado que veteranos envolvidos nos conflitos no Golfo Pérsico, na Bósnia e em Kosovo, em que munições baseadas em urânio exaurido foram intensamente utilizadas, têm até 14 vezes o nível normal de anomalias cromossômicas em seus genes (59) (60).

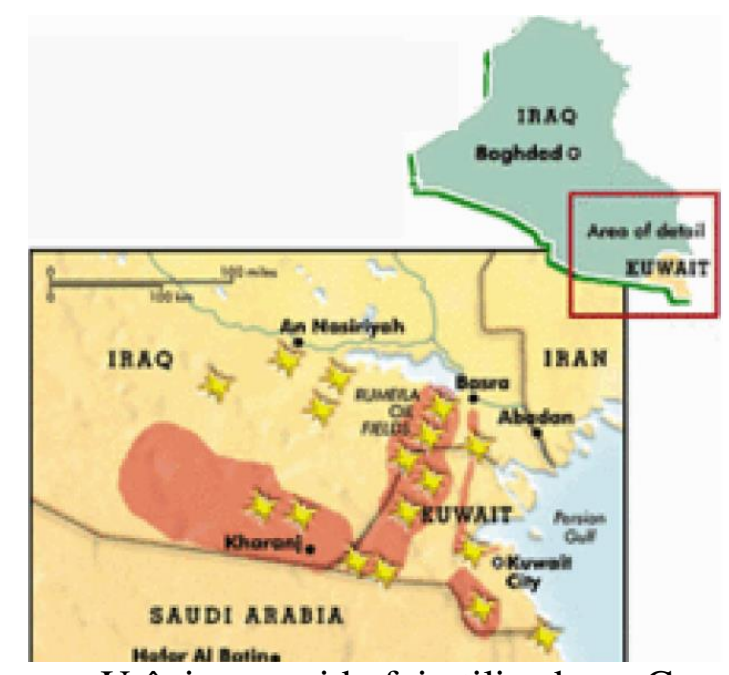

Figura 3. Áreas em que Urânio exaurido foi utilizado na Guerra do Golfo (61)

A evidência epidemiológica é consistente com o aumento do risco de defeitos de nascença na prole de pessoas expostas ao DU. Um estudo de 2001 com 15.000 veteranos de combate da Guerra do Golfo e 15.000 veteranos de controle, não envolvidos no conflito, descobriu que os ex-combatentes expostos tinham 1,8 vezes (militares pais) a 2,8 vezes (militares mães) mais probabilidade de ter filhos com defeitos de nascença (62).

\subsubsection{Primeira e segunda Guerra do Golfo - População Iraquiana}

Desde 2001, ou seja, uma década após a primeira Guerra do Golfo, foi constado pelas equipes de atendimento do hospital Basra, no sul do Iraque, um aumento acentuado na incidência de leucemia infantil e malformação genética entre bebês nascidos, como mostrado no gráfico da Figura 4. 


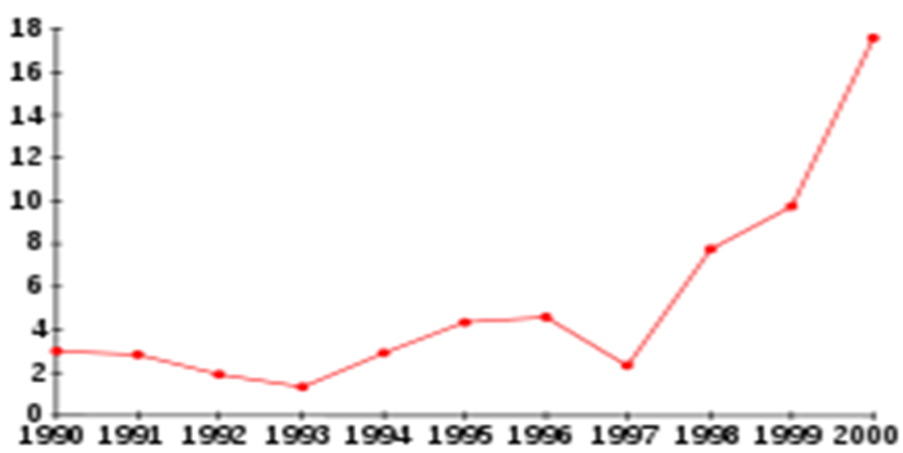

Figura 4. Gráfico com a taxa por 1.000 nascimentos com malformações congênitas observadas no Hospital Universitário de Basra, Iraque (61).

Os médicos iraquianos atribuíram essas malformações a possíveis efeitos de longo prazo do DU, uma opinião que foi repetida por vários jornais (63) (64) (65). Em 2004, o Iraque teve a maior taxa de mortalidade por leucemia entre todos os países em que esse registro é feito (66) (67). Os médicos iraquianos e várias entidades internacionais, incluindo a Royal Society e a Coalizão Internacional para a Proibição de Armas de Urânio, solicitou aos países ocidentais, que implementassem estudos epidemiológicos rigorosos na região, o que não foi feito (68) (69).

Uma pesquisa médica, "Taxa de câncer, mortalidade infantil e sexo ao nascer em Fallujah, Iraque 2005-2009", publicada em julho de 2010, afirmou que "... o aumento do câncer e defeitos congênitos ...é assustadoramente alto" e que a mortalidade infantil de 2009/2010, cinco anos após a segunda guerra do Golfo foi atingiu 13,6\%. O relatório mencionou o urânio exaurido como uma "exposição potencialmente relevante", mas não houve comprovação científica direta e conclusiva (70).

\subsubsection{Conflito dos Balcãs}

Em 1999, no conflito localizado ocorrido nos Balcãs, região da Europa oriental envolvendo principalmente a região do Kosovo, mostrada na Figura 5, foi a segunda grande utilização de munição de urânio empobrecido, implementada pelas forças da OTAN. 


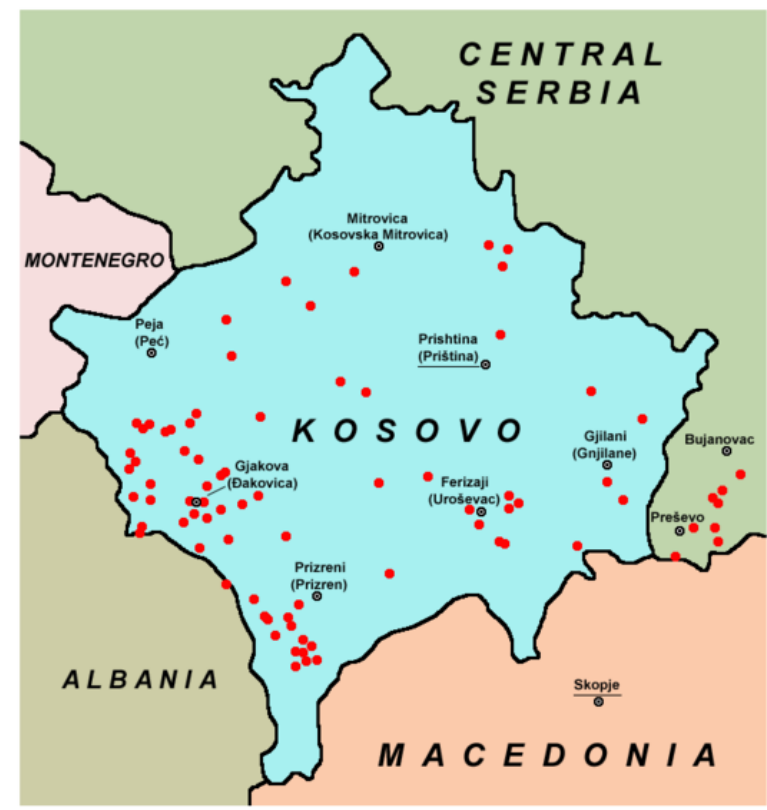

Figura 5. Locais em Kosovo e no centro-sul da Sérvia onde a aviação da OTAN usou urânio exaurido durante a Guerra de Kosovo de 1999 (71)

Em 2001, governos de vários países europeus, particularmente Itália, relataram um aumento nas doenças e desenvolvimentos de câncer entre os veteranos que serviram em missões de manutenção da paz nos Balcãs (71).

Um estudo de 2003, do Programa das Nações Unidas para o Meio Ambiente (UNEP), declarou que baixos níveis de contaminantes foram encontrados na água potável e partículas de ar nos pontos de impacto dos penetradores de DU. Os níveis foram declarados como não sendo motivo de alarme (72).

Em 2018, a Sérvia criou uma comissão de inquérito sobre as consequências do uso de urânio empobrecido durante o bombardeio da OTAN de 1999 e sua ligação com o aumento de doenças e tumores entre os cidadãos, especialmente em crianças nascidas depois de 1999 (73).

\subsubsection{Questões de segurança logísticas e ambientais}

Cerca de $95 \%$ do urânio empobrecido produzido até agora é armazenado como hexafluoreto de urânio, em cilindros de aço em pátios a céu aberto próximos às usinas de enriquecimento, como mostrado na Figura 6. Cada cilindro contém até 12,7 toneladas (14 toneladas dos EUA) de $\mathrm{UF}_{6}$. Em 2005, 686.500 toneladas em 57.122 cilindros de armazenamento metálicos já tinham se acumulado, somente nos Estados Unidos (74) (75). 


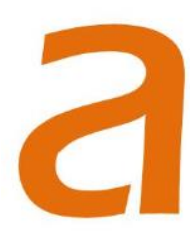

TAS Journal, vol. 4, n. 4, p. 219 - 240

ISSN 2595-1521

DECEMBER 2020

pedro.poveda@usp.br

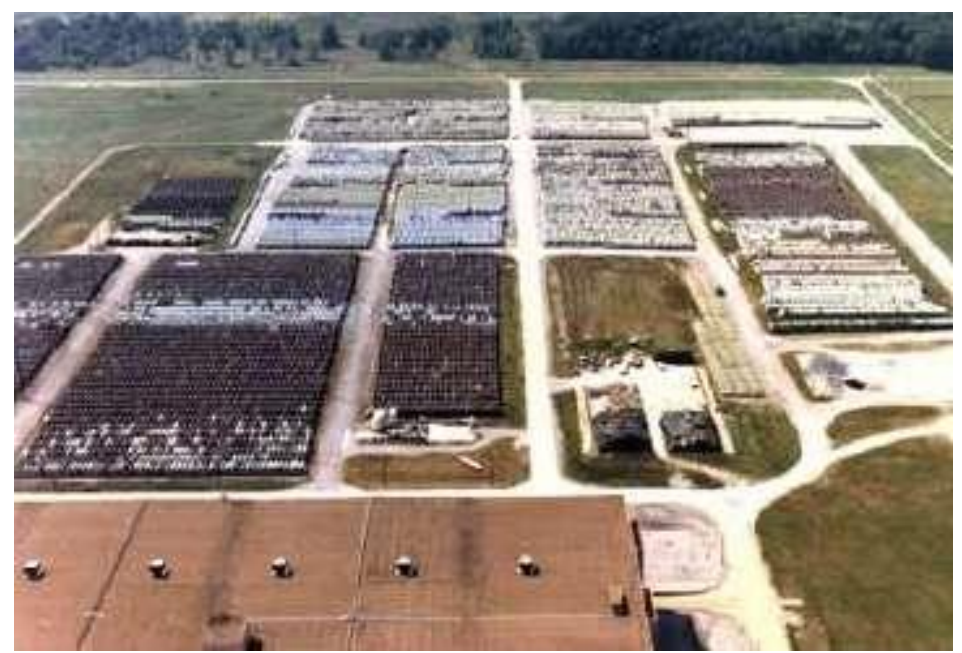

Figura 6. Armazenamento de $\mathrm{UF}_{6}$ a céu aberto nos Estados Unidos (74)

$\mathrm{O}$ armazenamento por longo prazo de $\mathrm{UF}_{6}$ apresenta riscos ambientais, de saúde e segurança devido à sua instabilidade química. Quando exposto ao ar úmido, reage com a água do ar e produz $\mathrm{UO}_{2} \mathrm{~F}_{2}$ (fluoreto de uranila) e $\mathrm{HF}$ (fluoreto de hidrogênio), ambos altamente solúveis e tóxicos. Os cilindros de armazenamento devem ser inspecionados regularmente com relação à indícios de corrosão e vazamentos e serem submetidos à manutenção preventiva e corretiva, quando necessário. A vida útil estimada dos cilindros de aço é medida em décadas, mas podem se deteriorar em prazos menores em razão de variações ambientais como mostrado na Figura 7 (76).

Houve vários acidentes envolvendo hexafluoreto de urânio nos Estados Unidos (77). A vulnerabilidade dos cilindros de armazenamento a ataques terroristas não é, aparentemente, abordada em relatórios públicos.
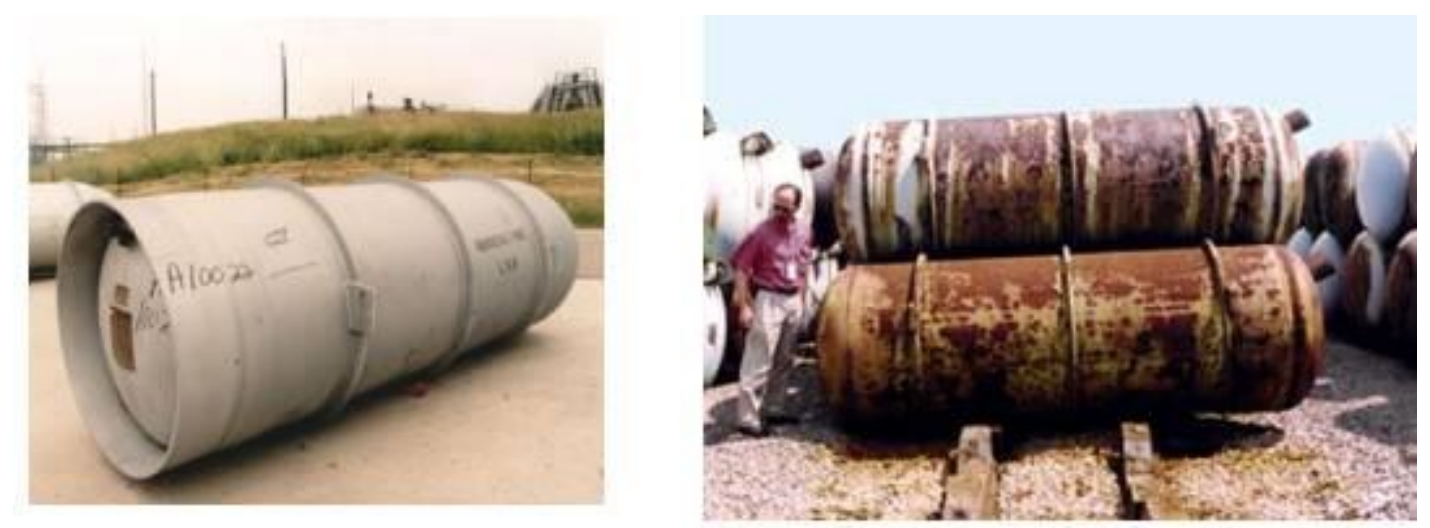

Figura 7. Tanques de armazenamento de $\mathrm{UF}_{6}$ intactos (à esquerda) e oxidados (à direita) (76) 


\section{CONCLUSÕES}

São relativamente recentes os problemas decorrentes da estocagem de grandes volumes de urânio exaurido e suas aplicações até o momento, na maioria controversas, como utilização em munições. Atenções foram dadas aos efeitos do DU após seu uso generalizado na Guerra do Golfo, como incorporação ao corpo através da pele, efeitos no trato respiratório e da exposição oral.

Embora a maior parte do DU absorvido no corpo seja metabolizado e excretado, uma quantidade suficiente é distribuída em todo o corpo podendo levar a efeitos toxicológicos importantes. Os efeitos de longo prazo do DU ainda precisam ser estudados (41), principalmente com apoio e adesão de agências governamentais no financiamento de pesquisas conclusivas.

Está se tornando cada vez mais claro que o impacto psicológico e de saúde, pós-conflitos militares, decorrentes da utilização de munições com DU, sobre os civis exigem um exame mais minucioso. Mais atenção também deve ser focada na redução da probabilidade de exposições de civis para aqueles que vivem e trabalham nas áreas afetadas.

Embora o debate sobre o impacto do DU na saúde humana ainda esteja em curso, fica claro, a partir da abordagem adotada por militares, que os riscos são reais e que devem ser tomadas medidas de precaução.

A organização civil IKV Pax Christi da Holanda (78), que há vários anos estuda os problemas envolvendo urânio esgotado, elaborou as seguintes recomendações:

1. Transparência dos estados envolvidos e causadores, sobre local onde o DU foi usado. Isso deve incluir o tipo e quantidade de munição e coordenadas GPS. Essas informações devem ser compartilhadas com órgãos governamentais relevantes e organizações internacionais ativas nas áreas afetadas;

2. Devem ser elaborados protocolos claros sobre a eliminação, descontaminação e armazenamento seguro de DU por especialistas em reconstrução pós-conflito e implementada nas áreas afetadas após os conflitos armados, seja pelos governos locais como por organizações internacionais;

3. O financiamento deve ser disponibilizado pela comunidade internacional para limpar áreas contaminadas, implementar programas de conscientização quando apropriado, e monitorar tanto o meio ambiente quanto a saúde da população local;

4. Os Estados devem compartilhar experiências e apoiar programas de capacitação nas áreas afetadas, tanto em desminagem, descontaminação e pesquisa em saúde e meio ambiente;

5. Os Estados devem considerar quais são as implicações da utilização do DU pósconflito, inclusive nas suas próprias tropas, para uma reavaliação da conveniência da sua utilização generalizada.

Outro caminho possível é se encontrar uma destinação mais "nobre" para o urânio exaurido que tem se acumulado ao longo dos anos. Por exemplo, em reatores nucleares de potência, para geração de energia elétrica. Atualmente, se encontram em desenvolvimento, Reatores Nucleares de Geração IV (também chamados reatores de última geração), esses reatores, na sua maior parte, possibilitarão o uso do DU como combustível, bem como, de outros subprodutos de fissão, provenientes das centenas de reatores atualmente em operação no mundo. 
Essa nova "família" de reatores deverá começar a operar na década de 2030 e apresenta grande potencial para mitigar os problemas de gestão de resíduos nucleares.

\section{REFERÊNCIAS}

(1) UNEP. Press Release UNEP/81: Uranium 236 found in depleted uranium penetrators. Disponível em<https://web.archive.org/web/20070412120641/http://www.deploymentlink.osd.mil/du_librar y/du_balkans/fig 1.htm> Acessado em 10/2020.

(2) US Public Health Service. Agency for Toxic Substances and Disease Registry (1999). Toxicological profile for uranium. Washington, DC.

(3) U.S. Office of the Secretary of Defense. Properties and Characteristics of DU.

(4) MILLER A. C., McClain D. (2007 Jan-Mar). A review of depleted uranium biological effects: in vitro and in vivo studies. Rev Environ Health. 22 (1): 75-89. PMID 17508699.

(5) Health Effects of Uranium. Toxicological profile for uranium.

(6) DIEHL, P. (1999). Depleted Uranium: A By-product of the Nuclear Chain. International Network of Engineers and Scientists Against Proliferation. 13.

(7) HAMILTON D. (25 January 2001). NATO: 50 Countries See No Depleted Uranium Illness. Reuters Health Information.

(8) HASTINGS D. (12 August 2006). Is an Armament Sickening U.S. Soldiers? Associated Press.

(9) OAKFORD, Samuel (14 February 2017). The United States Used Depleted Uranium in Syria. Foreign Policy.

(10) Energy Solutions. History of Depleted Uranium and What It Is Used For. 2015.

(11) Wayback Machine, anl.gov. How much depleted uranium hexafluoride is stored in the United States. 2007.

(12) Web.ead.anl.gov. Depleted UF6 Management Program Documents. 2008.

(13) Web.ead.anl.gov. FAQ 30-Have there been accidents involving uranium hexafluoride? 2008.

(14) Depleted Uranium Inventories. Retrieved 26 February 2016. Disponível em <http://www.wise-uranium.org/eddat.html> Acessado em 10/2020

(15) de JESUS, A. G. Urânio Empobrecido Na Produção De Munições Cinéticas Para Carros De Combate: Análise De Seu Uso Potencial. Departamento de Química da Academia Militar das Agulhas Negras (AMAN). Revista "Ação de Choque”. 2018. Disponível em < file://C:/Users/pedro/Downloads/1765-Texto\%20do\%20artigo-3833-1-10-20181008.pdf> Acessado em 10/2020.

(16) CANO, T. M. Tungstênio. Revista "Sumário Minineral”. Departamento Nacional de Produção Mineral (DNPM). 2011. Disponível em < https://sistemas.anm.gov.br/publicacao/mostra_imagem.asp?IDBancoArquivoArquivo=6397\#: : text=A\%20China\%20possui\%2065\%25\%20das,e \%20no\%20Canad\%C3\%A1\%20(4\%25).\&text 
TAS Journal, vol. 4, n. 4, p. 219 - 240

ISSN 2595-1521

DECEMBER 2020

pedro.poveda@usp.br

$=\mathrm{Al} \% \mathrm{C} 3 \% \mathrm{~A} 9 \mathrm{~m} \% 20 \mathrm{disso} \% 2 \mathrm{C} \% 20 \mathrm{a} \% 20 \mathrm{China} \% 20 \% \mathrm{C} 3 \% \mathrm{~A} 9$,que $\% 20$ mais $\% 20$ consome $\% 20$ tun gst\%C3\%AAnio\%20mundo> Acesso em 10/2020.

(17) PEACOCK, H. B. (March 1992). Pyrophoricity of Uranium. Westinghouse Savannah River Company. p. 2. Retrieved 3 May 2015. Disponível em < https://sti.srs.gov/fulltext/WSRC-TR92-106.pdf> Acessado em 10/2020.

(18) United States Department of Energy. Primer on Spontaneous Heating and Pyrophoricity. Doe Handbook. 2015. Disponível em < https://web.archive.org/web/20150904034407/http://energy.gov/sites/prod/files/2015/01/f19/DO E-HDBK-1081-2014.pdf> Acessado em 10/2020.

(19) Advisory Opinion 1996 July 8; General List No. 95 (req: UNGA) Archived 22 May 2014 at the Wayback Machine. Cornnet.nl. Retrieved 16 January 2011.

(20) Office of the United Nations High Commissioner for Human Rights, Geneva, Switzerland. Depleted Uranium UN Resolutions. Prop1.org. Retrieved 16 January 2011. Disponível em <http://www.prop1.org/2000/du/resource/000310un.htm> Acessado em 10/2020.

(21) UNHCHR. Open document Sub-Commission resolution. 1997. Disponível em < http://ww7.unhchr.ch/> Acessado em 10/2020.

(22) ONU "Human rights and weapons of mass destruction, or with indiscriminate effect, or of a nature to cause superfluous injury or unnecessary suffering". United Nations Economic and Social Council. 2002, authorized Mr. Y.K.J. Yeung Sik Yuen to prepare, without financial implications, in the context of human rights and humanitarian norms, the working paper originally assigned to Ms. Forero Ucros. Disponível em < https://documentsddsny.un.org/doc/UNDOC/GEN/G02/141/67/PDF/G0214167.pdf?OpenElement> Acessado em $10 / 2020$.

(23) SILLS, J. et al. Environmental Crimes in Military Actions and the International Criminal Court (ICC) - United Nations Perspectives of American Council for the UN University. 2002. p. 28 Archived 26 March 2009 at the Wayback Machine.

(24) ONU. Archived 6 August 2009 at the Wayback Machine. Final Report to the Prosecutor by the Committee Established to Review the NATO Bombing Campaign Against the Federal Republic of Yugoslavia Disponível em https://web.archive.org/web/20090806072638/http://www.un.org/icty/pressreal/nato061300.htm \#IVA2> Acessado em 10/2020.

(25) European Parliament. Session Document: European Parliament resolution on the harmful effects of unexploded ordnance (landmines and cluster submunitions) and depleted uranium ammunition. 2004. Disponível em < http://www.eoslifework.co.uk/pdfs/EUweaponsres12f03.pdf $>$ Acessado em 10/2020.

(26) European Parliament. European Parliament Makes Fourth Call for DU Ban. The International Coalition to Ban Uranium Weapons. 2006.

(27) OTAN. DU: Some NATO Countries Reject Moratorium. UN Wire. 2001. Disponível em < http://www.converge.org.nz/pma/durej.htm > Acessado em 10/2020.

(28) The Prime Minister's Office. Depleteduranium - epetition reply. 2007. Arc. Disponível em<https://web.archive.org/web/20070514012751/http://www.number10.gov.uk/output/Page113 09.asp> Acessado em 10/2020. 
TAS Journal, vol. 4, n. 4, p. 219 - 240

ISSN 2595-1521

DECEMBER 2020

pedro.poveda@usp.br

(29) ONU. Jump up to:a b United Nations General Assembly Session 62. The Acting President. 2007. Disponível em < https://en.wikipedia.org/wiki/United_Nations_General_Assembly > Acessado em 10/2020

(30) United Nations General Assembly Session 62 Verbotim Report 61. A/62/PV.61 page 25.

Mr. De Klerk Netherlands 5 December 2007. Retrieved 21 August 2008.

(31) ONU "UN Department of Public Information: Effects of the use of Armaments and Ammunitions Containing Depleted Uranium (A/C.1/63/L.26)" (Press release). UN. 2 December 2008. GA/10792. See draft XIV and Annex XIII

(32) UK Uranium Weapons Network launched as Belgium becomes first country to ban depleted uranium weapons Archived 3 March 2016 at the Wayback Machine. Bandepleteduranium.org (2009-06-22). Retrieved 16 January 2011.

(33) "Belgian Senate votes to ban investments by Belgian financial institutions into uranium weapon manufacturers" (PDF). 2013. Disponível em < https://www.dekamer.be/FLWB/PDF/52/1935/52K1935001.pdf > Acessado em 10/2020. (34) INO. The INC IR-100 Gamma Ray Camera". 2007. Disponível em < https://web.archive.org/web/20070930093916/http://www.ir100.com/PROD01.html > Acessado em 10/2020.

(35) WISE URANIUM. Depleted Uranium found as Coloring Matter in Enamel (France).

Disponível em < http://www.wise-uranium.org/dviss.html\#ENAMELF > Acessado em 10/2020. (36) SMETSERS, R.C.; WITLOX, H.W.; KRUS, H.W.; EISENGA, A.H. (2000). Evaluating the risk from depleted uranium after the Boeing 747-258F crash in Amsterdam, 1992. Journal of Hazardous Materials. 76 (1): 39-58. doi:10.1016/S0304-3894(00)00183-7. PMID 10863013. (37) US Department of Aviation. AC20-123 Avoiding or Minimizing Encounters with Aircraft Equipped with Depleted Uranium Balance Weights during Accident Investigations. Disponível em < https://www.faa.gov/documentLibrary/media/Advisory_Circular/AC20-123.pdf > Acessado em 10/2020.

(38) VOLVO OCEAN RACE. Roaring Forties, chapter 22: France's inspiration. 2013.

Disponível em < https://archive.theoceanrace.com/en/news/7245_Roaring-Forties-chapter-22Frances-inspiration.html > Acessado em 10/2020

(39) An Experiment at D0 to Study anti-Proton - Proton Collisions at 2-TeV: Design Report.

(40) ZEUS. The ZEUS detector: Status Report 1993. Disponível em < https://wwwzeus.desy.de/bluebook/ch05/chapter2_4.html > Acessado em 10/2020

(41) CRAFT, E. S. et al. Depleted and natural uranium: chemistry and toxicological effects. Journal of Toxicology and Environmental Health - Part B: Critical Reviews. Duke University, Durham, North Carolina, USA. 2004.

(42) Archived 4 September 2011 at the Wayback Machine. Disponível em <web.archive.org> Acessado em 10/2020.

(43) Royal Society Working Group on the health hazards of depleted uranium munitions (2001). "The health hazards of depleted uranium munitions: Part I". London: The Royal Society. "The health hazards of depleted uranium munitions: Part II". London: The Royal Society. Briefly, inhaled and insoluble means that the DU particles will stick around in the lungs and attendant 
TAS Journal, vol. 4, n. 4, p. 219 - 240

ISSN 2595-1521

DECEMBER 2020

pedro.poveda@usp.br

lymph nodes, presenting a radiological risk; highly soluble means those particles are off to the kidneys, where toxicity is the issue.

(44) MITSAKOU, C; ELEFTHERIADIS, K; HOUSIADAS, C; LAZARIDIS, M. 2003.

Modeling of the dispersion of depleted uranium aerosol. Health Phys. 84 (4): 538-44.

doi:10.1097/00004032-200304000-00014. PMID 12705453. S2CID 3244650.

(45) Susan Taylor Martin (25 May 2003). How harmful is depleted uranium? St. Petersburg Times.

(46) Health Effects of Uranium. Toxicological profile for uranium. Archived from the original on 23 November 2007. Disponível em <

https://web.archive.org/web/20071123082540/http://fhp.osd.mil/du/healthEffects.jsp > Acessado em 10/2020.

(47) ZWIJNENBURG, Wim (2012). Hazard Aware: Lessons learned from military field manuals on depleted uranium and how to move forward for civilian protection norms. Utrecht: IKV Pax Christi. ISBN 978-9-070-44327-6.

(48) Jump up to:a b Norton-Taylor, Richard (11 January 2001). MoD knew shells were cancer risk. theguardian.com. Retrieved 29 August 2013.

(49) MOSZYNSKI, Peter (2003). Royal Society warns of risks from depleted uranium. BMJ. 326 (7396): 952. doi:10.1136/bmj.326.7396.952. JSTOR 25454350. PMC 1125878. PMID 12727744.

(50) Williams, M. (9 February 2004) First Award for Depleted Uranium Poisoning Claim,The Herald Online, (Edinburgh: Herald Newspapers, Ltd.).

(51) MILLER, A. C.; STEWART, M.; BROOKS, K.; SHI, L.; PAGE, N. (2002). Depleted uranium-catalyzed oxidative DNA damage: absence of significant alpha particle decay. Journal of Inorganic Biochemistry. 91 (1): 246-252. doi:10.1016/S0162-0134(02)00391-4. PMID 12121782.

(52) MILlER, A. C.; STEWART, M.; BROOKS, K.; SHI, L.; PAGE, N. (2002a). Depleted uranium-catalyzed oxidative DNA damage: absence of significant alpha particle decay. Journal of Inorganic Biochemistry.

(53) LIVENGOOD, D. R. (1996). Introduction to the Problem. Health Effects of Embedded Depleted Uranium Fragments. Bethesda, Maryland: Armed Forces Radiobiology Research Institute. pp. 3-6.

(54) KRANE, K. S. The amounts of both thorium-234 and protactinium-234 after the first days and for millions of years thereafter will be approximately proportional to $1-2-\mathrm{t} /$ ( 24 days). 1988. Introductory Nuclear Physics. ISBN 978-0-471-80553-3.

(55) MURPHY, Fran M. (1999). Gulf war syndrome: There may be no specific syndrome, but troops suffer after most wars. BMJ. 318 (7179): 274-275. doi:10.1136/bmj.318.7179.274.

JSTOR 25181681. PMC 1114762. PMID 9924035.

(56) ROKKE, D. radical.org. 10 November 2000. Address on Depleted Uranium. Disponível em $<$ https://ratical.org/radiation/DU/DRonDU2000.html > Acessado em 10/2020.

(57) COKER, W. J.; BHATT, B. M.; BLATCHLEY, N. F.; GRAHAM, J. T. (1999). Clinical findings for the first 1000 Gulf war veterans in the Ministry of Defence's medical assessment 
programme. BMJ. 318 (7179): 290-294. doi:10.1136/bmj.318.7179.290. JSTOR 25181700. PMC 27710. PMID 9924053.

(58) U.S. Research Advisory Committee on Gulf War Veterans' Illnesses (2004). Scientific Progress in Understanding Gulf War Veterans' Illnesses: Report and Recommendations. Archived 31 December 2006 at the Wayback Machine.

(59) FLEMING, N.; TOWNSEND, M. (11 August 2002). Gulf veteran babies 'risk deformities. The Observer. London. Retrieved 29 August 2013.

(60) ARFSTEN, D. P.; STILL, K. R.; RITCHIE, G. D. (2001). A review of the effects of uranium and depleted uranium exposure on reproduction and fetal development. Toxicology and Industrial Health. 17 (5-10): 180-191. doi:10.1191/0748233701th111oa. PMID 12539863115. (61) AL-SADOON, I. et al., writing in the Medical Journal of Basrah University, (see Table 1 here) Archived 28 September 2011 at the Wayback Machine. This version from data by same author(s) in Wilcock, A. R., ed. (2004). Uranium in the Wind. (Ontario: Pandora Press) ISBN 09736153-2-X. S2CID 25310165.

(62) KANG, H.; et al. (2001). Pregnancy Outcomes Among U.S. Gulf War Veterans: A Population-Based Survey of 30,000 Veterans. Annals of Epidemiology. 11 (7): 504-511. doi:10.1016/S1047-2797(01)00245-9. PMID 11557183.

(63) NEUFFER, E. Iraqis. Trace Surge in Cancer to US Bombings. Archived 2 September 2013 at the Wayback Machine Boston Globe 26 January 2003, Page: A11 Section: National/Foreign. (64) JOHNSON, L. Iraqi cancers, birth defects blamed on U.S. depleted uranium. Archived 20 November 2008 at the Wayback Machine Seattle Post-Intelligencer 12 November 2002. Retrieved 25 January 2009.

(65) MCKAY, R. (14 January 2001). "Depleted Uranium: The Horrific Legacy of Basra".

Sunday Herald. Scotland. Archived from the original on 27 May 2013. Retrieved 15 February 2013.

(66) WHO Data, 2004. Retrieved 4 September 2013. Disponível em <https://www.who.int/entity/healthinfo/global_burden_disease/gbddeathdalycountryestimates20 04.xls > Acessado em 10/2020.

(67) SIMONS, M. Doctor's Gulf War Studies Link Cancer to Depleted Uranium. nytimes.com. 29 January 2001. Disponível em < https://www.nytimes.com/2001/01/29/world/doctor-s-gulfwar-studies-link-cancer-to-depleted-uranium.html > Acessado em 10/2020.

(68) MOSZYNSKI, Peter (2003). Royal Society warns of risks from depleted uranium. BMJ. 326 (7396): 952. doi:10.1136/bmj.326.7396.952. JSTOR 25454350. PMC 1125878. PMID 12727744. [69] 144. ^ Support the Basra Epidemiological Study, International Coalition to Ban Uranium Weapons

(70) MANTELERO, A. Depleted uranium legal aspects (Italy) 2009-2011 7-05-2011. Disponível em < https://staff.polito.it/alessandro.mantelero/DUP.html > Acessado em 10/2020.

(71) SIMONS, Marlise (7 January 2001). Radiation From Balkan Bombing Alarms Europe. The New York Times. Disponível em < https://www.nytimes.com/2001/01/07/world/radiation-frombalkan-bombing-alarms-europe.html > Acessado em 10/2020.

(72) ONU. Low-level DU contamination found in Bosnia and Herzegovina, UNEP calls for precaution. United Nations Environment Programme, 2003. Disponível em < 
https://web.archive.org/web/20040411033334/http://www.unep.org/Documents.Multilingual/Def ault.asp?DocumentID=298\&ArticleID=3926\&l=en > Acessado em 10/2020.

(73) GOCANIN, S. Serbian Accusation Lingers Of Link Between NATO Bombing, Health Woes. Radio Free Europe/Radio Liberty. 2019.

(74) Web.ead.anl.gov. FAQ 16-How much depleted uranium hexafluoride is stored in the United States?. 2007. Disponível em

<https://web.archive.org/web/20071223063911/http://web.ead.anl.gov/uranium/faq/storage/faq1 6.cfm > Acessado em 10/2020.

(75) Web.ead.anl.gov. Uranium Documents. 2008. Disponível em <

https://web.archive.org/web/20080216013118/http://web.ead.anl.gov/uranium/documents/index. cfm > Acessado em 10/2020

(76) IEE. Science-Based Stockpile Stewardship (Vol. 5, No. 2)". 2016. Disponível em < https://ieer.org/article/science-for-democratic-action/volume-5-number-2/ > Acessado em $10 / 2020$.

(77) Web.ead.anl.gov. Have there been accidents involving uranium hexafluoride? 2008. Disponível em <

https://web.archive.org/web/20080306020031/http://web.ead.anl.gov/uranium/faq/health/faq30.c $\mathrm{fm}>$ Acessado em 10/2020.

(78) IKV Pax Christi. HAZARD AWARE: Lessons learned from military field manuals on depleted uranium and how to move forward for civilian protection norms. Utrecht. The Netherlands. 2001. Disponível em <www.ikvpaxchristi.nl> Acessado em 10/2020. 